Composites Science \& Technology, 2012. 72(8): 924-932.

http://dx.doi.org/10.1016/j.compscitech.2012.03.003

\title{
Predicting mode-II delamination suppression in z-pinned laminates
}

Francesco Bianchi, Xiang Zhang ${ }^{1}$

Aerospace Engineering Dept, School of Engineering, Cranfield University, Cranfield, MK43 0AL, UK

\begin{abstract}
A finite element model for predicting delamination resistance of z-pin reinforced laminates under the mode-II load condition is presented. End notched flexure specimen is simulated using a cohesive zone model. The main difference of this approach to previously published cohesive zone models is that the individual bridging force exerted by z-pin is governed by a specific traction-separation law derived from a unit-cell model of single pin failure process, which is independent of the fracture toughness of the unreinforced laminate. Therefore, two separate traction-separation laws are employed; one represents unreinforced laminate properties and the other for the enhanced delamination toughness owing to the pin bridging action. This approach can account for the so-called large scale bridging effect and avoid using concentrated pin forces in numerical models, thus removing the mesh-size dependency and permitting more accurate and reliable computational solutions.
\end{abstract}

Keywords: B. Delamination; B. Fracture; C. Finite element analysis (FEA); C. Multiscale modelling; Z-pins.

\section{Introduction}

There have been many published research papers on z-pinned laminates under the mode II fracture, for example, experimental investigation [1-7], analytical models including the mixed mode delamination [4, 8-12], and numerical models [13-16]. Failure characteristics and z-pin delamination suppression mechanism are well understood. Z-pin bridging effect has been modelled by either averaging the bridging forces over the entire reinforced area $[8,13,17]$ or nonlinear springs exerting concentrated traction force at the pin location [2, 14-16]. Usually the bridging force is not constant during crack growth due to the pin's local effect; therefore enhanced fracture toughness is not best represented by averaging the traction forces. On the other hand, using concentrated forces in numerical models can cause stress singularities, consequently the solution can be mesh dependent. To overcome these difficulties, cohesive zone models (CZM) have been used recently for modelling adhesive failure or delamination in both pinned [17] and unpinned laminates [18-21] with encouraging results.

\footnotetext{
${ }^{1}$ Corresponding author

Email addresses: xiang.zhang@ cranfield.ac.uk (X. Zhang); f.bianchi@ cranfield.ac.uk (F. Bianchi)
} 
However, there is still the need for more robust and efficient analysis models for design purpose. Models are also needed for recently developed structures reinforced by larger diameter rods or protrusions, e.g. hybrid metal-composite joints [22-24].

In [25] a novel approach based on the cohesive fracture model is presented for predicting the mode I delamination suppression in z-pinned laminates. It is different from the current methods in the open literature that use either an average value of enhanced toughness or CZM for unpinned area only. Rather, two separate cohesive laws are employed to represent the delamination toughness of the unpinned and pinned areas, respectively.

This paper is sequential to [25] using similar approach but focusing on the mode II load condition. Due to the pin's nonlinear behaviour under the mode II load and deformation mode switch from bending dominant to axial tension, single pin pullout model presented in this paper is different from that of the model I model in [25]. Pin bridging law is determined analytically using the classic beam theory that is subsequently implemented into a macroscale model of the End Notched Flexure (ENF) geometry. Predicted forces vs. displacement relation and delamination growth curve are validated by published test results.

\section{Modelling strategy}

The model is presented in Fig 1. Fracture mechanics theory on strain energy balance in zpinned laminates can be found in [25]. The idea is to use two traction-separation laws (TSL) representing the unpinned laminate and pinned locations respectively. The unpinned TSL is governed by the intrinsic toughness of the laminate, whereas the pin bridging force offers much enhanced toughness in pin locations. A multi-scale model has been developed. Firstly, the pin bridging force is evaluated by an analytical unit-cell model of single-pin accounting for two failure modes: pin rupture or pullout. The resultant bridging law is then implemented in a macro-scale structural model. This modelling approach has the advantage of accounting for the local enhancement effect due to z-pins, avoiding either averaging the pin forces over the whole reinforcement area or using concentrated pin forces. The large scale bridging effect is better represented.

\section{Single-pin pullout model}

\subsection{Model description}

A single pin unit-cell model under the mode II load is shown in Fig. 2a. It comprises a laminate with a centre delamination and a z-pin. Assuming the pin's chamfer end is negligible, the specimen is symmetric with respect to the central plane and is loaded anti- 
symmetrically. Therefore only one half of the pin is modelled. Considering that pin pullout is more likely to occur at the part with the chamfer, pin insertion depth in the model is reduced by the chamfer size. All aforementioned three phases are modelled. During the elastic response the pin is assumed to react as a beam supported by an elastic spring foundation. Stiffness of the spring foundation is estimated by the elastic properties of the nearby laminate using the dimension of the resin rich zone around the pin. Since the resin rich pocket extends in the fibre direction and the laminate properties in the cross-fibre direction are dominated also by the resin, material properties close to the pin are assumed to be homogeneous and isotropic, and equal to the transverse stiffness of the surrounding laminate.

During the elastic deformation phase pin's lateral displacement $u$ can be expressed by following differential equation:

$$
E I \frac{\partial^{4} u}{\partial z^{4}}+k u=0
$$

where $E I$ is the pin's bending rigidity, $k$ the elastic constant of the spring foundation mimicking the stress distribution in the laminate acting on the pin, which is calculated by:

$$
k=\frac{\pi}{2} \frac{E_{\text {lam }}}{\ln \left(\frac{R}{r_{0}}\right)}
$$

where $r_{0}$ and $R$ are radius of the pin and resin rich zone, which is usually 4-6 times of the pin radius (in this model $R=5 r_{0}$ ). Derivation of eq. (2) is given in Appendix A.

Let $\delta$ be the applied shear displacement between the two laminate parts and set the following boundary conditions:

$$
u(h)=\frac{\delta}{2}, \quad u^{\prime \prime}(h)=0, \quad u^{\prime \prime}(0)=0 \quad u^{\prime \prime \prime}(0)=0
$$

During the pin ploughing phase laminate is assumed to react as a perfectly plastic material; the lateral force exerted on the pin is therefore constant and independent of the displacement. The force per unit length $(p)$ represents the resistance of the laminate being punched by a blunt notch $[5,9]$. The model is shown in Fig. 2b. Following differential equation describes the pin's lateral displacement in the ploughing zone.

$$
N \frac{\partial^{2} u}{\partial z^{2}}+\frac{\partial N}{\partial z} \frac{\partial u}{\partial z}=p
$$


where $N$ is the axial stress on the pin and $p$ the lateral reaction force per unit length acting on the laminate. Derivation of eq. (4) can be found in Appendix B. Differential eqs. (1) and (4) describe z-pin displacement in the transverse direction. Eq. (4) depends on the distribution of the axial stress in the pin. The friction resistance is the physical mechanism by which pin carries axial load. Following differential equation, derived from the force balance in the pin axial direction, describes pin's axial stress distributed along the axis:

$$
\left\{\begin{array}{cc}
\frac{\partial N}{\partial z}=\mu\left(\sigma_{0}+k|u|\right) & x \leq h_{t} \\
\frac{\partial N}{\partial z}=\mu p & h_{t}<x \leq h
\end{array}\right.
$$

where $\mu$ is the Coulomb friction coefficient between pin and laminate, $\sigma_{0}$ the compressive residual stress arising from the curing process and $h_{t}$ the length of transition between the elastic and plastic behaviour. Note that $h_{t}$ is not constant during the simulation. The transition is assumed to occur when the pin starts having large lateral displacements, thus when the shear strength $\left(S_{u}\right)$ is exceeded the pin will split into several ligaments. Initial stress $\sigma_{0}$ is estimated by the following equation.

$$
\sigma_{0}=\frac{\Delta T\left(\alpha_{\text {lam }}-\alpha_{p i n}\right) E_{\text {lam }} E_{p i n}}{E_{\text {lam }}+E_{p i n}}
$$

where temperature difference $\Delta T=150^{\circ} \mathrm{C}$, coefficients of thermal expansion of the pin and laminate are $\alpha_{\text {pin }}=0$ and $\alpha_{\text {lam }}=2.4 \times 10^{-5} \mathrm{~K}^{-1}$. The mathematical problem is solved using the boundary condition of the axial stress (Fig. 2b):

$$
N(L)=F \sin (\alpha)
$$

The extent of ploughing depends on the applied load magnitude (it is larger if the load increases); therefore a nonlinear solution has been found using an iterative scheme as illustrated in Fig. 3, which is implemented in a Matlab 7 computer program. The maximum bridging force is estimated by considering two critic conditions that lead two failure modes: (1) axial stress exceeds the friction resistance resulting in the pin being pulled out; (2) axial stress overcomes z-pin tensile strength causing the pin rupture failure.

\subsection{Results}

Fig. 4 shows the force vs. displacement relationship of different configurations: a) variable pin diameter at fixed laminate thickness (Fig. 4a, 4b) variable laminate thickness for a given 
pin diameter (Fig. 4b). All plots show similar characteristics as described below: (1) an initial linear elastic response before force reaches $20 \mathrm{~N}$, after which point the pin is subjected to larger deformation and ploughing into the laminate. During the ploughing phase despite the curve becomes more compliant it continuously increases to a maximum value. At this peak force one of the two failures occur: pin abrupt rupture resulting in sudden drop of the reaction force, or pin is gradually pulled out manifesting a linear decrease of the bridging force. When the pin is completely pullout, the displacement equals to the pin embed length. Another failure mode is abrupt pin rupture manifesting a sudden force drop (Fig. 4). Following observations can be made: (1) both laminate thickness and pin diameter influence the pin pullout behaviour; the load carrying capability is higher for larger pin diameter and thicker laminates; (2) pin rupture is more likely to occur for smaller diameter pins or pins inserted in thicker laminates; (3) initial stiffness and maximum elastic force are higher for bigger pins.

Calibration of model parameters was performed using the test data published in [3]. Fig. 5 shows a comparison of the calculated and test measured bridging force vs. displacement. In the test pin were not placed exactly perpendicular to the laminate plane; there was a small deviation to the intended insertion angle ${ }^{2}$ (Fig. 5). This is characteristic of the technology currently used; therefore, more realistic traction-separation law should be an average of all the possible bridging forces coming from different insertion angles within the range. However, these considerations are beyond the scope of this paper; the pin is thus modelled as perpendicular to the laminate plane.

Two parameters have been used to calibrate the model: the friction coefficient $\mu$ and the laminate punch strength $p$, which is defined in $[5,10]$. The first parameter controls the occurrence of pin pullout; the higher the friction coefficient, the longer the pullout is delayed and the higher the ultimate bridging force. The second changes the curvature of the upward curve representing the pin's nonlinear response as described by eq. (4). Higher punch strength results in less surrounding material being affected by pin ploughing; thus stiffer response of the pin (upward curve). Calibrated model parameters by the test data are given in Table 1.

\section{ENF model}

\subsection{Model assumptions}

\footnotetext{
${ }^{2}$ Minus sign in pin angle means the pin tip towards opposite direction of applied load.
} 
Pinned and unpinned ENF specimens shown in Fig. 6 are taken from [1]. They were made of 24 ply unidirectional prepreg IMS/924 resulting in $3 \mathrm{~mm}$ nominal thickness ${ }^{3}$. Laminate mechanical properties are listed in Table 2 . An initial crack of $25 \mathrm{~mm}$ was made by inserting a thin polyamide film in the mid-plane of each specimen. Z-pins were made of pultruded T300/BMI. Reinforced area was designed $5 \mathrm{~mm}$ from the initial crack tip ${ }^{4}$ extending for 25 $\mathrm{mm}$ length covering the entire specimen width. Three configurations of different pin areal density or diameter were simulated; these parameters are summarised in Fig. 6 insert.

Only half of a pin row and surrounding laminate are modelled by exploiting the pin periodical arrangement. This unit strip model was previously employed to simulate the mode-I fracture [25]. Eight-node linear continuum shell elements with reduced integration (designated as CS8R in ABAQUS) were used for the laminates and 8-node cohesive elements (COH8) for the bonding interface. For numerical stability cohesive element size is one fifth of the adjacent shell element (Fig. 7). Therefore, this 2D shell element model has one layer of shell elements for each half of the ENF.

The bridging force vs. crack opening displacement relation shown in Fig. 5 is nonlinear in the curve's rising part. In order to implement this bridging law into a macro-scale FE model, i.e. ENF in this paper, a traction-separation law in terms of the pin stress is deduced from the bridging force shown in Fig. 5; it is expressed as:

$$
T(u)=\frac{P(u)}{\pi r_{0}^{2}}
$$

where $u$ is the shear displacement, $T(u)$ the bridging stress in the pin and $P(u)$ the bridging force. Eq. (8) is plotted in Fig. 8 (solid line represents the realistic bridging law). The bilinear curve (dashed line) is an approximation. The two curves are equivalent in terms of the enhanced fracture energy $\left(G_{I I C}^{p i n}\right)$, which is the area under the stress-displacement curve; both curves describe same energy absorption rate due to pin bridging effect.

This pin response was implemented into the global FE model of the ENF specimen using two different pin models to represent the nonlinear and bilinear bridging laws as shown in Fig. 7 insert. (1) The "spring-pin" model employs nonlinear spring elements with a user-defined force-displacement relation, which is the nonlinear curve in Fig. 8. As depicted in Fig. 7

\footnotetext{
${ }^{3}$ Measured thickness is $3.2 \mathrm{~mm}$ for unpinned and pinned configuration 1 specimens, $3.3 \mathrm{~mm}$ for pinned specimens in configurations 2 and 3 (Fig. 7 insert).

${ }^{4}$ Actual measured distance from first pin row to initial crack tip was $1 \mathrm{~mm}$ for all configurations.
} 
insertion (a) these springs are connected to the laminate beams through the Multiple-Point Constraints (MPC). The size of the connection points equals the pin cross-sectional area. (2) The "cohesive-pin" model uses cohesive elements at the interface that are governed by the simplified bilinear traction-separation law. In both models the plain adhesive toughness is modelled by cohesive elements governed by a traction-separation law characteristic of the unpinned laminate. Published test data of unreinforced ENF were used to correlate the cohesive model parameters, which are given in Table 3.

Boundary condition of the unit strip model is set according to the periodic pin arrangement, i.e. the two longitudinal planes that delimit half of a pin row are constrained not having the $y$ direction displacement during the simulation. Load is applied by displacement controlled loading condition, i.e. a transverse displacement $\delta$ is imposed at the centre of the ENF.

\subsection{Results and discussion}

\subsubsection{Force vs. applied displacement}

Predicted force vs. displacement of three z-pin configurations are shown in Figs. 9a-11a. Both the cohesive-pin and spring-pin models predict similar force-displacement responses. Cohesive-pin model predicts a slightly higher force and shorter crack extension when the crack size is small $(<4 \mathrm{~mm})$, and two models get closer for larger crack lengths. Difference between the two predictions always remains within 5\%, demonstrating that the simplified bilinear bridging law works well. For the $2 \%$ pin density cases, the spring-pin model had some difficulty to converge, as the simulation stopped at about $4 \mathrm{~mm}$ of applied displacement (marked by asterisk symbol in Fig. 9a, 10a). On the contrast the cohesive-pin model always reached the end of simulation due to the more robust formulation. For the lower pin density $\left(A_{\mathrm{p}}=0.5 \%\right)$, spring-pin model ran through. Due to the convergence difficulties the number of incremental steps is much larger for the spring-pin model than that of the cohesive-pin model; consequently, the computing time for the spring-pin model is about four times higher. Overall predicted force-displacement curves are in good agreement with the test results in [1] for all the three cases.

\subsubsection{Crack bridging length}

The pin bridging effect starts as soon as delamination crack passes the first pin row. Crack tip is shielded from shear stress as pins bridge the crack wake; hence the applied load recovers from the initial drop and increases to a maximum. Crack bridging length is a good indicator of the bridging effect, which is defined as the length of the crack wake where the pins are active, 
i.e. not failed completely. Number of active pin rows is presented in Figs. 9a-11a indicated on the right-hand $y$-axis. In all three cases the number of active pin rows increases continuously and does not reach a saturate value; it increases up to the total number of pin rows inserted in the laminate. Specimen's final failure occurs due to the laminate crushing failure under bending. This result is in agreement with the constant rising resistance curve ( $R$-curve) in [1], where it reports that mode-II fracture toughness of z-pinned laminates constantly increases with the increasing crack length. The absence of a plateau in the $R$-curve indicates that the number of active pins in the crack wake is still increasing just before the final failure.

\subsubsection{Crack extension behaviour}

Crack length vs. applied displacement is plotted in Figs. 9b-11b. It is worth noting that in the experiment crack lengths were measured by visual observation; therefore, the comparison of test with models is more for the trend rather than being quantitative. The agreement between the simulation and experiment is reasonably good, particularly for the $2 \%$ pin density cases and the $0.5 \%$ case when crack is below $15 \mathrm{~mm}$, with percentage error less than $20 \%$. Larger discrepancy is noted for longer cracks (>15 mm) when it is close to specimen's final failure. Cohesive-pin model predicts slightly shorter crack length due to employing the simplified bilinear traction-separation law; the pins have stiffer response than the pins modelled by the springs. However, apart from the initial difference in crack growth length, two models converge in all modelled cases due to the equivalence in the critical strain energy release rates described by the two bridging laws.

\subsubsection{Interlaminar shear stresses}

Fig. 12 shows the interlaminar shear stresses at the delamination plane at applied displacement of $4 \mathrm{~mm}$ (pin parameter $A_{\mathrm{p}}=2 \% ; d=0.51 \mathrm{~mm}$ ). Higher shear stresses are predicted by the cohesive-pin model on the pin rows close to the crack tip. This is because that the bilinear cohesive-pin model is stiffer than the spring-pin model before the force reaches the maximum (Fig. 8), hence the higher predicted pin reaction force. It is worth noting that the pin stresses in Fig. 12 should not be interpreted as the pin's internal stress, but an equivalent stress derived from bridging force per unit pin cross-sectional area.

\section{Concluding Remarks}

The main contribution of this paper is to demonstrate that: 1) z-pin bridging action can be modelled by nonlinear springs as well as cohesive elements. Bridging laws governing these 
pin models can be deduced from either single-pin specimen tests or unit-cell models; 2) these pin models can be implemented into a commercial FE package for structural models.

The second contribution is the development of a unit-cell model of single-pin pullout in mode II load condition. It can be used for predicting the bridging effect of different pin parameters once it is calibrated by testing one configuration.

\section{Acknowledgments}

The research is funded by UK Engineering and Physical Sciences Research Council (through the Cranfield University Innovative Manufacturing Research Centre). The authors also thank Prof IK Partridge and Dr DDR Cartié for providing experimental test data.

\section{Appendix A. Derivation of laminate stiffness in the unit-cell model}

Consider a section of a pin and surrounding laminate. A shear displacement $\delta$ is imposed to the pin cross section, which is assumed not to deform. The laminate subjected to a punch load deforms and the hosting hole is assumed having the eyelet shape as depicted in Fig. A1. In the following equations the reaction force provided by the laminate is expressed as a function of the applied displacement. The stiffness of the spring foundation can be calculated by dividing the reaction force by the applied displacement. Only one hemisphere of pin is assumed to contact with the laminate. Assuming the shear stress is negligible at the pin/laminate interface, the lateral force that laminate exerts on the pin can be expressed as:

$$
F=\int_{-\frac{\theta}{2}}^{\frac{\theta}{2}} \sigma_{r_{0}}(\theta) \cos (\theta) r_{0} d \theta
$$

Consider the force equilibrium in the radial direction, following relation can be written:

$$
r \frac{\partial \sigma_{r}}{\partial r}+\sigma_{r}-\sigma_{\theta}+\frac{\partial \tau_{r \theta}}{\partial \theta}=0
$$

Assuming circumferential stress $\sigma_{\theta}$ and shear stress $\tau_{r \theta}$ are negligible compared to $\sigma_{r}$, eq. (A2) can be written as:

$$
\frac{\partial\left(r \sigma_{r}\right)}{\partial r}=0
$$

This means that at a given angle $\theta$ the radial stress flow $r \sigma_{r}$ remains constant along the radial direction and this flow remains the same as the one at the pin/laminate interface $\left(r_{0} \sigma_{r_{0}}\right)$. 
Assuming the lateral displacement of the laminate is zero at sufficiently far distance from the pin $(r=R)$, the radial displacement of the laminate at the pin interface can be expressed as:

$$
\delta_{r_{0}}=\int_{r_{0}}^{R} \frac{\sigma_{r}}{E_{\text {lam }}}=\frac{r_{0} \sigma_{r_{0}}}{E_{\text {lam }}} \int_{r_{0}}^{R} \frac{d r}{r}=\frac{r_{0} \sigma_{r_{0}}}{E_{\text {lam }}} \ln \left(\frac{R}{r_{0}}\right)
$$

But the radial displacement has to be the same as the pin:

$$
\delta_{r_{0}}=\delta \cos (\theta)
$$

Using eqs. (A4) and (A5) $\sigma_{r_{0}}$ is written as function of $\delta$; substituting it in eq. (A1) we have:

$$
F=\frac{\delta E_{\text {lam }}}{\ln \left(\frac{R}{r_{0}}\right)} \int_{-\frac{\theta}{2}}^{\frac{\theta}{2}} \cos ^{2}(\theta) d \theta=\frac{\pi}{2} \frac{E_{\text {lam }}}{\ln \left(\frac{R}{r_{0}}\right)} \cdot \delta
$$

Eq. (A6) gives the elastic response of the laminate being punched by a pin.

\section{Appendix B. Derivation of z-pin differential equation after pin splitting}

Consider a z-pin section of unit length $d z$. Large lateral displacement causes internal splitting, which makes the pin completely flexible in bending. The pin is thus able to carry only the axial stress. The pin is assumed inextensible, i.e. having infinitely high axial stiffness. Let $N=$ $\pi r^{2} \sigma$ be the axial force of the pin, a schematic of the force acting over the pin is depicted in Fig. B1. The force equilibrium balance along the $z$ and $x$-axis can be written as follows:

$$
\left\{\begin{array}{l}
\left(N+\frac{\partial N}{\partial z} d z\right) \cos \left(\alpha+\frac{d \alpha}{d z} d z\right)-N \cos (\alpha)=q d z \\
\left(N+\frac{\partial N}{\partial z} d z\right) \sin \left(\alpha+\frac{d \alpha}{d z} d z\right)-N \sin (\alpha)=p d z
\end{array}\right.
$$

Assuming the derivative of $\alpha$ being small (small angle variations), eq. (B1) can be written as:

$$
\left\{\begin{array}{l}
\frac{\partial N}{\partial z}=q \\
\left(N+\frac{\partial N}{\partial z} d z\right)[\sin (\alpha) \overbrace{\cos \left(\frac{d \alpha}{d z} d z\right)}^{1}+\cos (\alpha) \overbrace{\sin \left(\frac{d \alpha}{d z} d z\right)}^{\frac{d \alpha}{d z} d z}]-N \sin (\alpha)=p d z
\end{array}\right.
$$

From geometrical consideration the following relation can be written: 


$$
\frac{d u}{d z}=\sin (\alpha), \quad \frac{d^{2} u}{d z^{2}}=\cos (\alpha) d \alpha
$$

Substituting eq. (B3) in (B2), we can obtain the following differential equation:

$$
\frac{\partial N}{\partial z} \frac{d u}{d z}+N \frac{d^{2} u}{d z^{2}}=p
$$

Which can also be expressed in a simpler form:

$$
\frac{\partial\left(N \frac{\partial(u)}{\partial z}\right)}{\partial z}=p
$$

\section{References}

1. Cartié DDR, Troulis M, Partridge IK. Delamination of Z-pinned carbon fibre reinforced laminates. Compos Sci Technol 2006; 66: 855-861.

2. Koh TM, Feih S, Mouritz AP. Experimental determination of the structural properties and strengthening mechanisms of z-pinned composite T-joints. Compos Struct 2011; 93: 2269-2276.

3. Cartié DDR, Cox BN, Fleck NA. Mechanisms of crack bridging by composite and metallic rods. Composites Part A 2004; 35: 1325-1336.

4. Cartié DDR, Dell'Anno G, Poulin E, Partridge IK. 3D reinforcement of stiffener-to-skin T-joints by z-pinning and tufting. Eng Frac Mech2006; 73: 2532-2540.

5. Plain KP, Tong L. Experimental validation of theoretical traction law for inclined throughthickness reinforcement. Compos Struct 2009; 91:148-157.

6. Rugg KL, Cox BN, Ward KE, Sherrick GO. Damage mechanisms for angled through-thickness rod reinforcement in carbon-epoxy laminates. Composites Part A 1999; 29: 1603-1613.

7. Rugg KL, Cox BN, Massabò R. Mixed mode delamination of polymer composite laminates reinforced through the thickness by the z-fibres. Composites Part A 2002; 33: 177-190.

8. Massabo R, Cox BN. Concepts for bridged Mode II delamination cracks. J Mech Phys Solids 1999; 47: 1265-1300.

9. Cox BN, Marshall DB. The determination of crack bridging forces. Int J Fracture 1991; 49:159176.

10. Cox BN, Shidhar N. A traction law for inclined fibre tows bridging mixed-mode cracks. Mech Adv Mater Struct 2002; 9:299-331.

11. Cox BN. Snubbing effects in the pullout of a fibrous rod from a laminate. Mech Adv Mater Struct 2005; 12: 85-98.

12. Plain KP, Tong L. Traction law for inclined through-thickness reinforcement using a geometrical approach. Compos Struct 2009; 88: 558-569. 
13. Tong L, Sun X. Bending effect of through-thickness reinforcement rods on mode II delamination toughness of ENF specimen: Elastic and rigid-perfectly plastic analyses. Composites Part A 2007; 38: 323-336.

14. Yan W, Liu H, Mai Y. Mode II delamination toughness of z-pinned laminates. Compos Sci Technol 2004; 64:1937-1945.

15. Allegri G, Zhang X. On the delamination and debond suppression in structural joints by z-fibre pinning. Composites Part A 2007; 38: 1107-1115.

16. Grassi M, Cox B, Zhang X. Simulation of pin-reinforced single-lap composite joints. Compos Sci Technol 2006; 66: 1623-1638.

17. Dantuluri V, Maiti S, Geubelle PH, Patel R, Kilic H. Cohesive modeling of delamination in Z-pin reinforced composite laminates. Composites Sci Technol 2007; 67: 616-631.

18. Borg R, Nilsson L, Simonsson K. Simulating DCB, ENF and MMB experiments using shell elements and a cohesive zone model. Composites Sci Technol 2004; 64: 269-278.

19. Sun CT, Jin Z. Modeling of composite fracture using cohesive zone and bridging models. Composites Sci Technol 2006; 66: 1297-1302.

20. Diehl T. On using a penalty-based cohesive-zone finite element approach, Part II: Inelastic peeling of an epoxy-bonded aluminum strip. Int J Adhes Adhes 2008; 28: 256-265.

21. Guiamatsia I, Davies GAO, Ankersen JK, Iannucci L. A framework for cohesive element enrichment, Composite Structures. Compos Struct 2010; 92: 454-459.

22. Ucsnik S, Scheerer M, Zaremba S, Pahr DH. Experimental investigation of a novel hybrid metalcomposite joining technology. Composites Part A 2010; 41: 369-374

23. Tu W, Wen PH, Guild FJ. Multi-region mesh free method for Comeld ${ }^{\mathrm{TM}}$ joints. Int J Comput Mater Sci 2010; 48: 481-489

24. Tu W, Wen PH, Hogg PJ, Guild FJ. Optimization of the protrusion geometry in Comeld ${ }^{\mathrm{TM}}$ joints. Compos Sci Technol 2011; 71: 868-876

25. Bianchi F, Zhang X. A cohesive zone model for predicting delamination suppression in z-pinned laminates. Compos Sci Technol 2011; 71:1898-1907. 


\section{Tables}

Table 1 Mechanical properties and parameters used in the unit-cell model.

\begin{tabular}{cccccc}
\hline $\begin{array}{c}\text { Z-pin } \\
\text { Young's } \\
\text { modulus }^{\text {a }}\end{array}$ & $\begin{array}{c}\text { Laminate } \\
\text { Young's } \\
\text { modulus }\end{array}$ & $\begin{array}{c}\text { Friction } \\
\text { coefficient }^{\text {c }}\end{array}$ & $\begin{array}{c}\text { Pin axial } \\
\text { strength }^{\text {a }}\end{array}$ & $\begin{array}{c}\text { Pin } \\
\text { shear } \\
\text { strength }^{\text {a }}\end{array}$ & $\begin{array}{c}\text { Laminate } \\
\text { punch }^{\text {strength }}{ }^{\text {c }}\end{array}$ \\
\hline $\begin{array}{c}E_{\text {pin }}(\mathrm{GPa}) \\
120\end{array}$ & $\begin{array}{c}E_{\text {lam }}(\mathrm{GPa}) \\
11\end{array}$ & $\mu$ & $S_{\text {pin }}(\mathrm{MPa})$ & $S_{u}(\mathrm{MPa})$ & $p(\mathrm{~N} / \mathrm{mm})$ \\
\hline
\end{tabular}

Date sources: a. from [26]; b. transverse stiffness of IMS/924 (Table 2); c. calibrated by test data in [3].

Table 2 Mechanical properties of IMS/924 [26]

\begin{tabular}{|c|c|c|c|c|c|c|c|c|}
\hline$E_{I}$ & $E_{2}$ & $\begin{array}{c}E_{3} \\
(\mathrm{GPa})\end{array}$ & $G_{12}$ & $G_{13}$ & $G_{23}$ & $v_{12}$ & $v_{13}$ & $v_{23}$ \\
\hline 138 & 11 & 11 & 4.4 & 4.4 & 3.92 & 0.34 & 0.34 & 0.4 \\
\hline
\end{tabular}

Table 3 Parameters used in the cohesive laws

\begin{tabular}{|c|c|c|c|c|c|c|}
\hline \multicolumn{3}{|c|}{ Plain laminate } & \multicolumn{4}{|c|}{ Pin bridging cohesive law } \\
\hline $\begin{array}{c}K_{I I} \\
\left(\mathrm{~N} / \mathrm{mm}^{3}\right)\end{array}$ & $\begin{array}{c}T_{I I 0} \\
(\mathrm{MPa})\end{array}$ & $\begin{array}{c}G_{I I C} \\
\left(\mathrm{~kJ} / \mathrm{m}^{2}\right)\end{array}$ & $\begin{array}{l}\text { Pin diameter } \\
(\mathrm{mm})\end{array}$ & $\begin{array}{c}K_{I I} \\
\left(\mathrm{~N} / \mathrm{mm}^{3}\right)\end{array}$ & $\begin{array}{c}T_{I I 0} \\
(\mathrm{MPa})\end{array}$ & $\begin{array}{c}G_{I I C}^{p i n} \\
\left(\mathrm{~kJ} / \mathrm{m}^{2}\right)\end{array}$ \\
\hline $1 \times 10^{5}$ & 30 & 0.77 & $\begin{array}{l}0.28 \\
0.51\end{array}$ & $\begin{array}{l}4.2 \times 10^{4} \\
1.9 \times 10^{4}\end{array}$ & $\begin{array}{r}1050 \\
630\end{array}$ & $\begin{array}{l}740 \\
370\end{array}$ \\
\hline
\end{tabular}


Figures

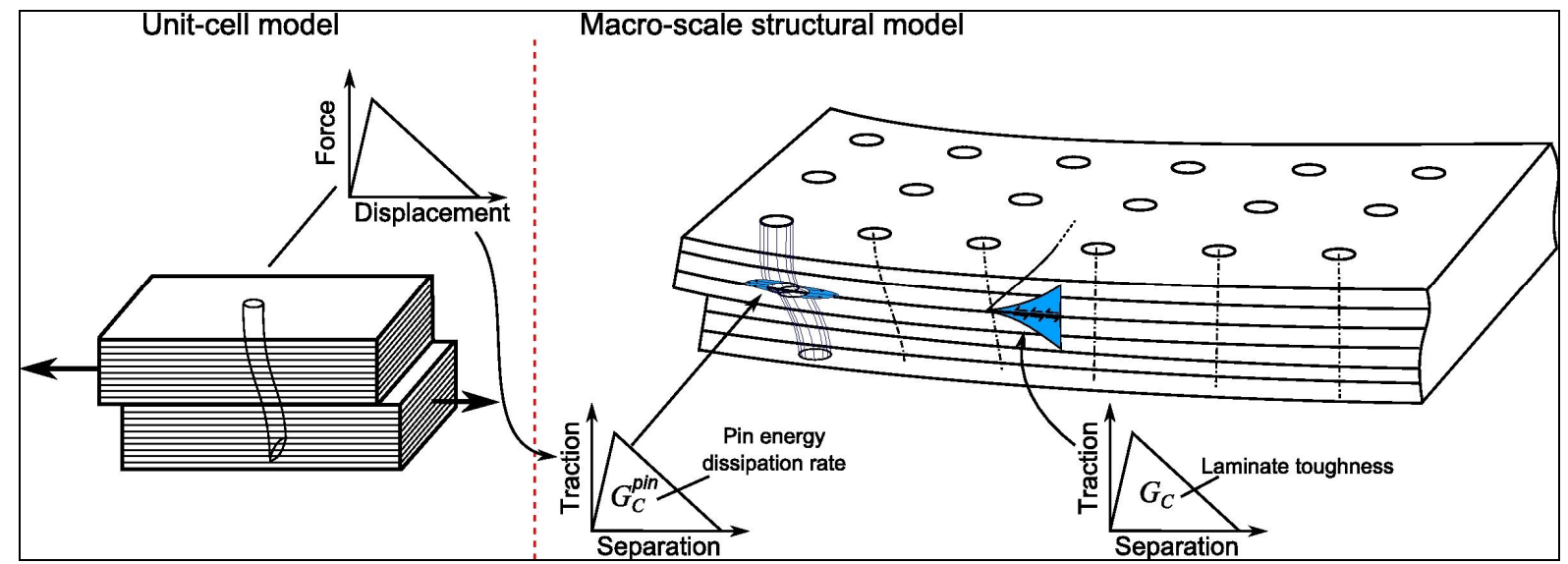

Fig.1. Modelling approach: z-pin bridging force is determined by a unit-cell model; the bridging law is applied at each pin position in a macro-scale structural model.

(a)

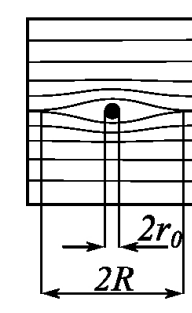

.

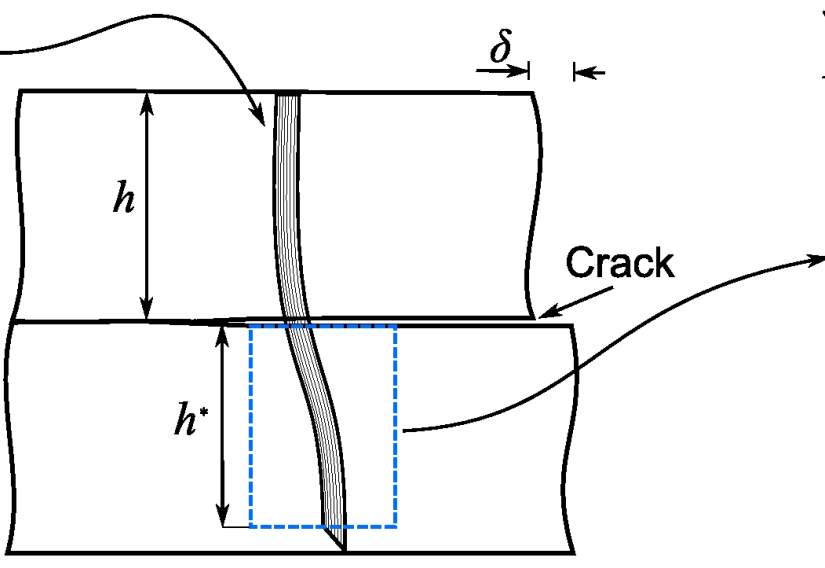

(b)

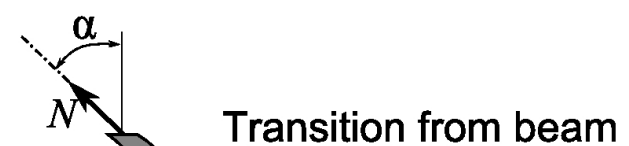
to truss behaviour

Fig.2. (a) Schematic of single-pin mode II model, (b) unit-cell model for evaluating the mode-II bridging law. 


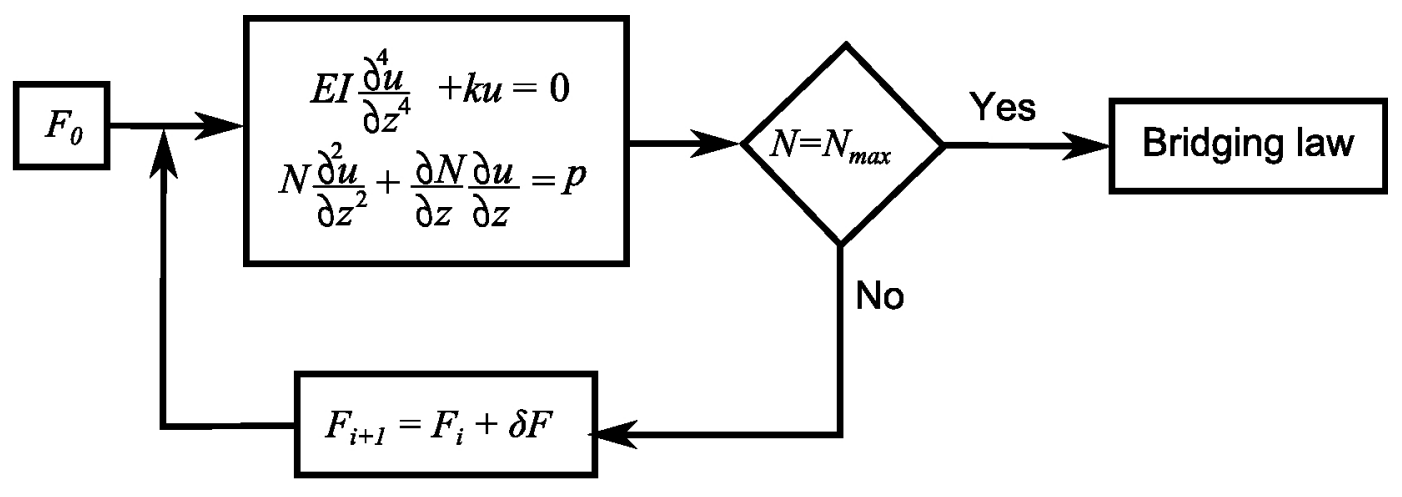

Fig.3. Iterative scheme used for determining the single-pin bridging force.

(a)

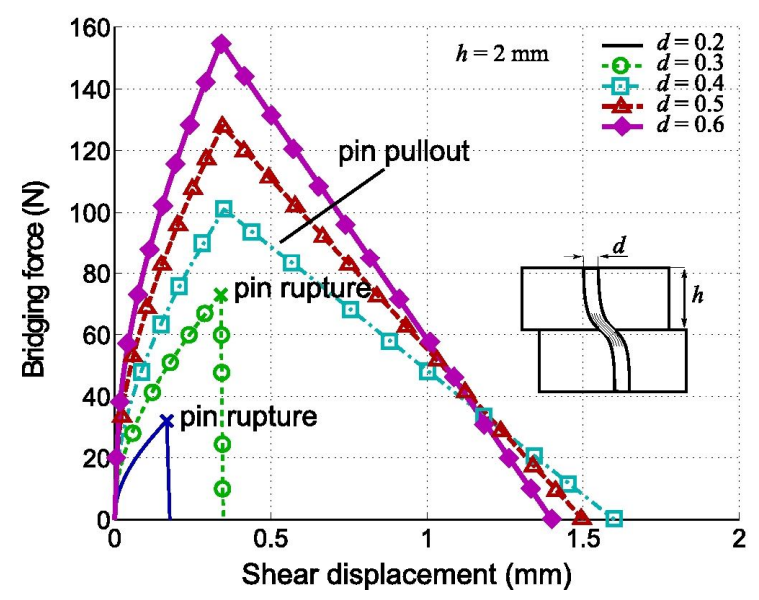

(b)

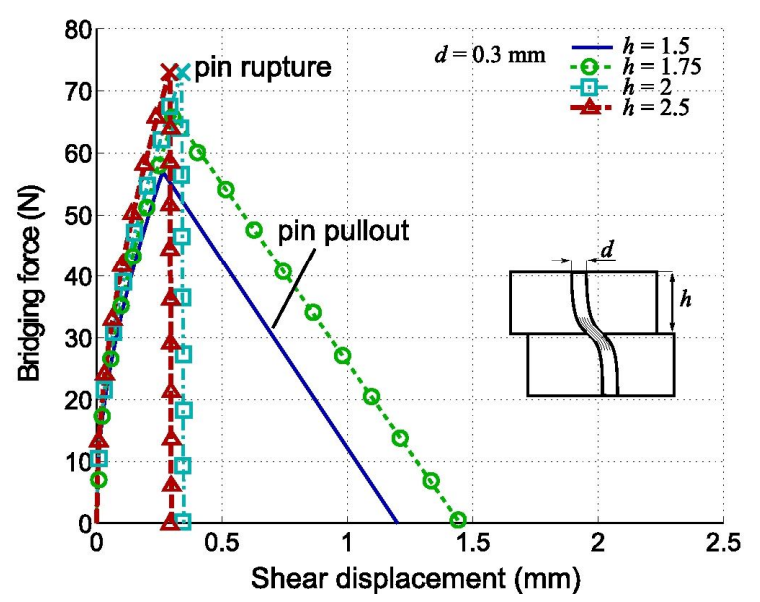

Fig.4. Influence of pin parameters on the bridging force: (a) effect of pin diameter, (b) effect of laminate thickness. 


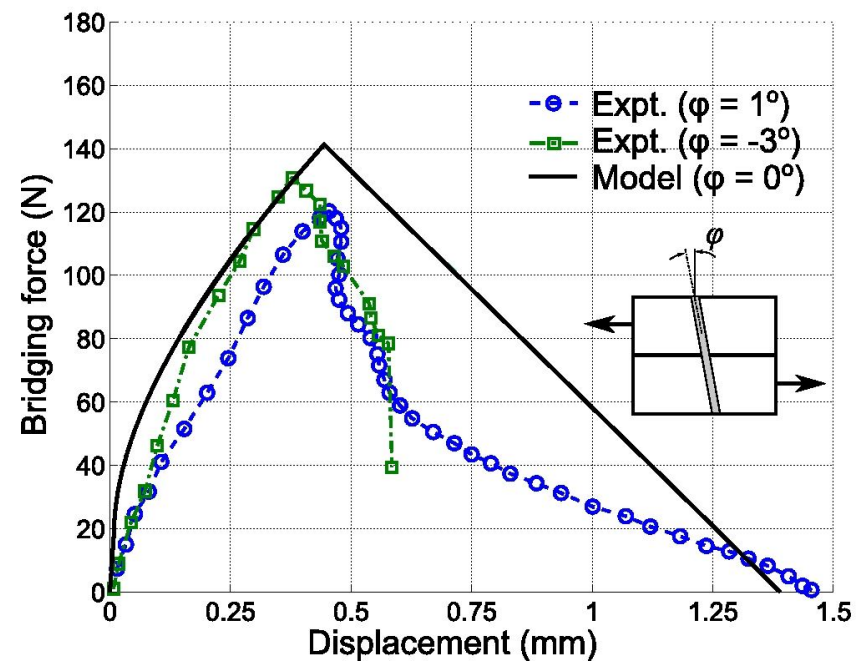

Fig. 5. Comparison of analytical model with experimental data [3] of single pin pullout test.

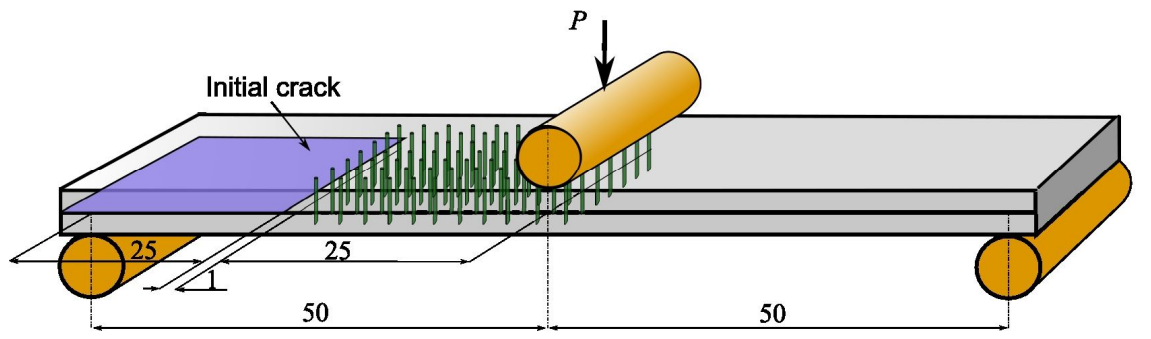

\begin{tabular}{llll}
\multicolumn{3}{l}{ Z-pin parameters } \\
\hline $\begin{array}{l}\text { Config. } \\
\text { No. }\end{array}$ & $\begin{array}{l}\text { Pin areal } \\
\text { density } \\
(\%)\end{array}$ & $\begin{array}{l}\text { Pin } \\
\text { diameter } \\
(\mathrm{mm})\end{array}$ & $\begin{array}{l}\text { Pin } \\
\text { pitch } \\
(\mathrm{mm})\end{array}$ \\
\hline 1 & 2 & 0.51 & 3.1 \\
2 & 2 & 0.28 & 1.55 \\
3 & 0.5 & 0.28 & 3.5
\end{tabular}

Fig. 6. ENF specimen geometry and dimensions (unit: $\mathrm{mm}$ ). 


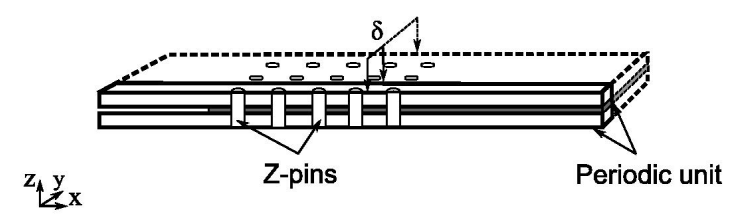

\begin{tabular}{ll} 
Element size & (unit $=\mathrm{mm}$ ) \\
\hline Free arm & $0.5 \times 0.3$ \\
Bonded side & $0.25 \times 0.25$ \\
Close to pins & $0.1 \times 0.1$
\end{tabular}
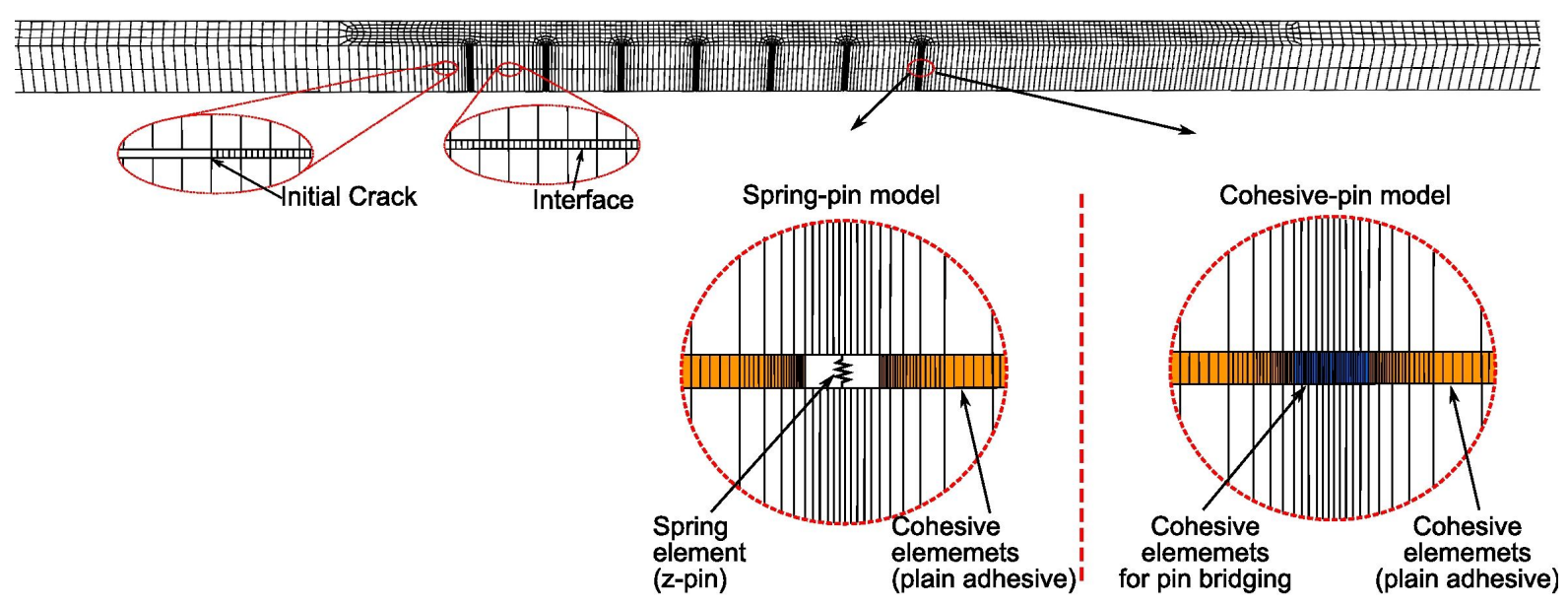

(z-pin)

(plain adhesive)

(a)

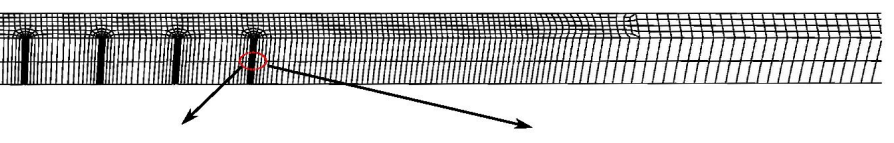

Fig. 7 Model of z-pinned ENF specimen using two layers of shell elements and cohesive elements at interface. Insertion (a) "spring-pin" model using a non-linear spring element; (b) "cohesive-pin" model using a cohesive traction-separation law for enhanced toughness at pin location.

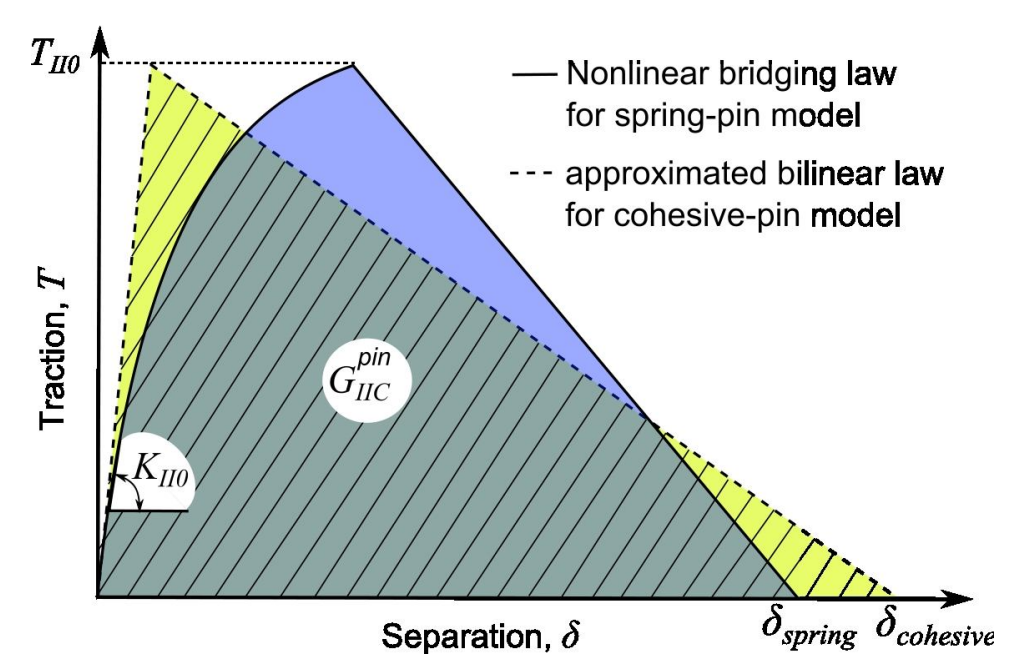

Fig. 8. Schematic of bridging laws used by the two single-pin models: non-linear law used for the "spring-pin" model derived by the analytical model and tuned by tests (Fig. 5), and simplified bi-linear traction-separation law for the "cohesive-pin" model. 

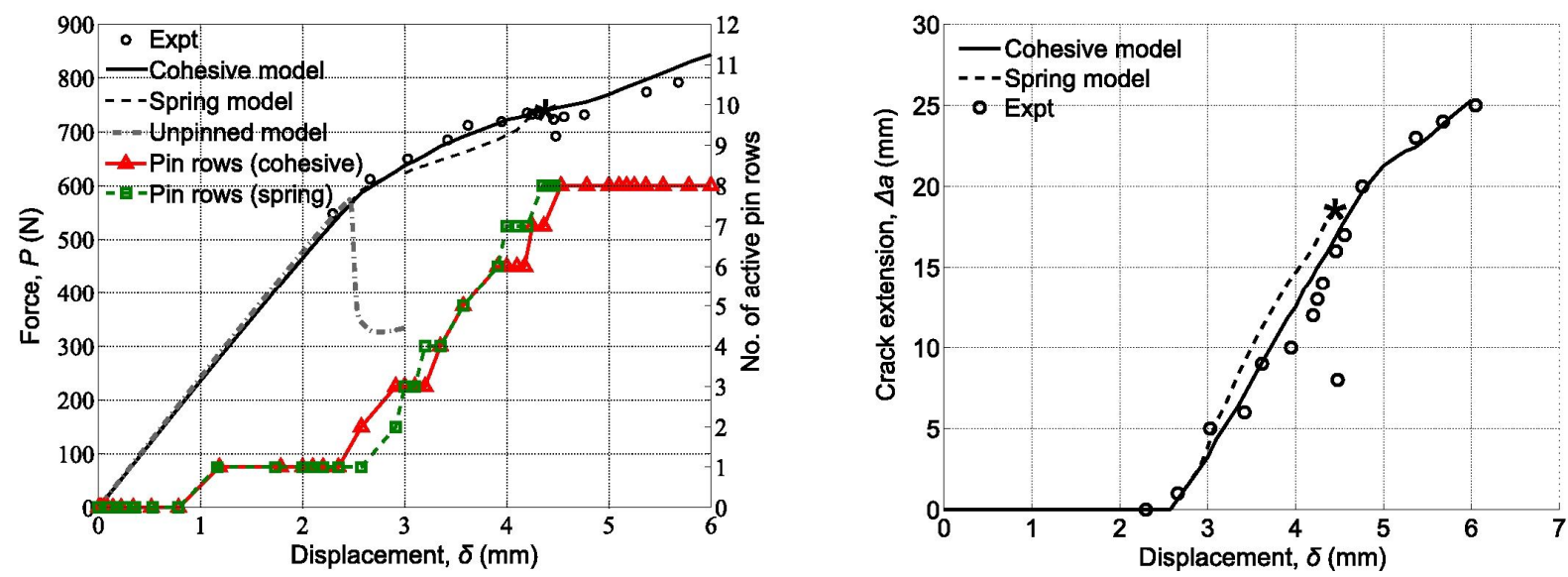

Fig. 9. Comparison between experiment and simulation (pinned laminate: $A_{\mathrm{p}}=2 \%, d=0.51 \mathrm{~mm}$ ), (a) applied force vs. displacement; also showing the number of active pin rows in the crack wake (right-hand $y$-axis), (b) crack extension vs. applied displacement.
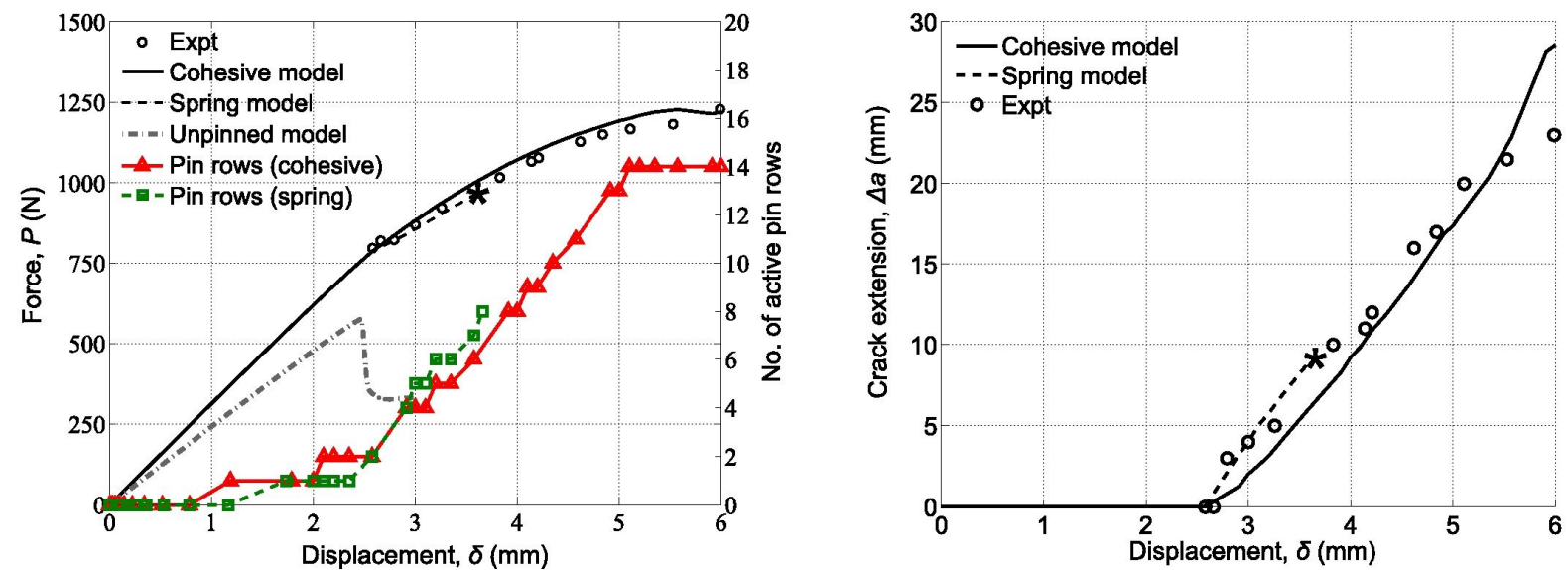

Fig. 10. Comparison between experiment and simulation (pinned laminate: $A_{\mathrm{p}}=2 \%, d=0.28 \mathrm{~mm}$ ), (a) applied force vs. displacement; also showing the number of active pin rows in the crack wake (right-hand $y$-axis), (b) crack extension vs. displacement. 

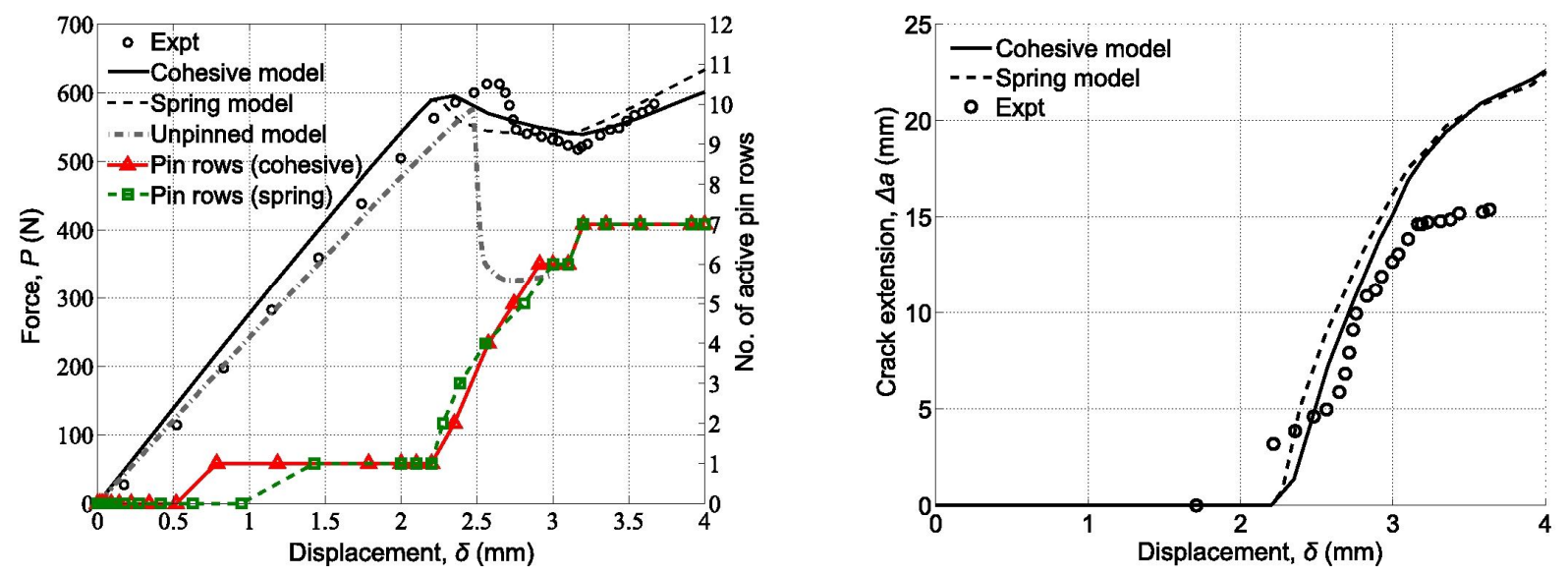

Fig. 11. Comparison between experiment and simulation (pinned laminate: $A_{\mathrm{p}}=0.5 \%, d=0.51 \mathrm{~mm}$ ), (a) applied force vs. displacement; also showing the number of active pin rows in the crack wake (right-hand $y$-axis), (b) crack extension vs. displacement.

(a)

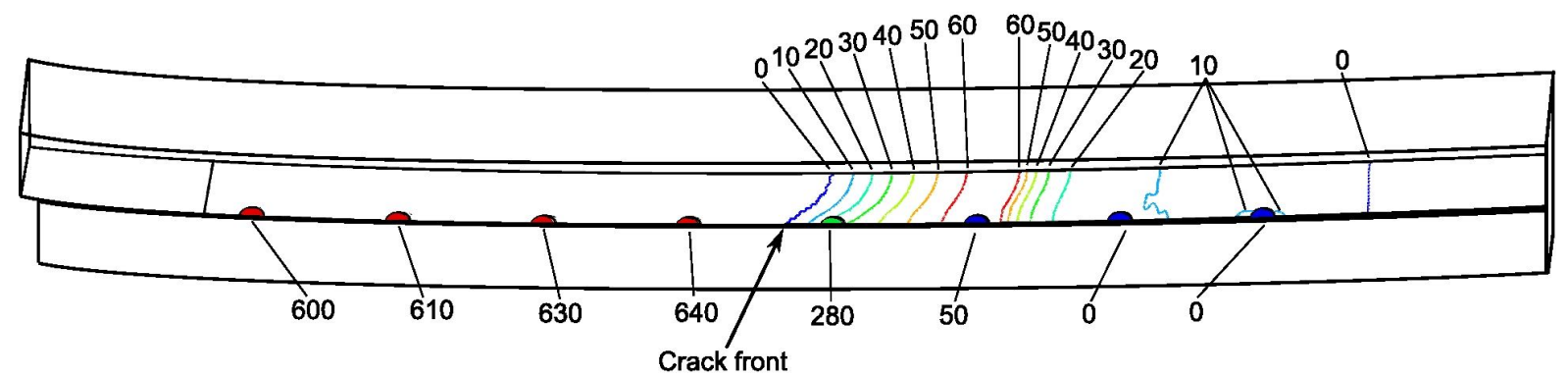

(b)

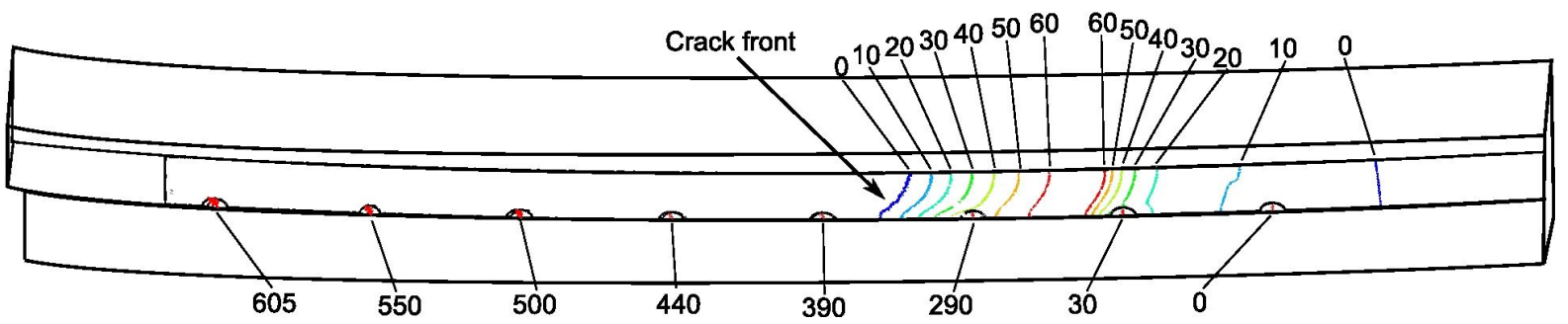

Fig.12: Interlaminar shear stresses at delamination plane, (a) cohesive-pin model, (b) spring-pin mode. (unit: MPa). Pinning parameters: $A_{\mathrm{p}}=2 \%, d=0.51 \mathrm{~mm}$; applied displacement $=4 \mathrm{~mm}$. 


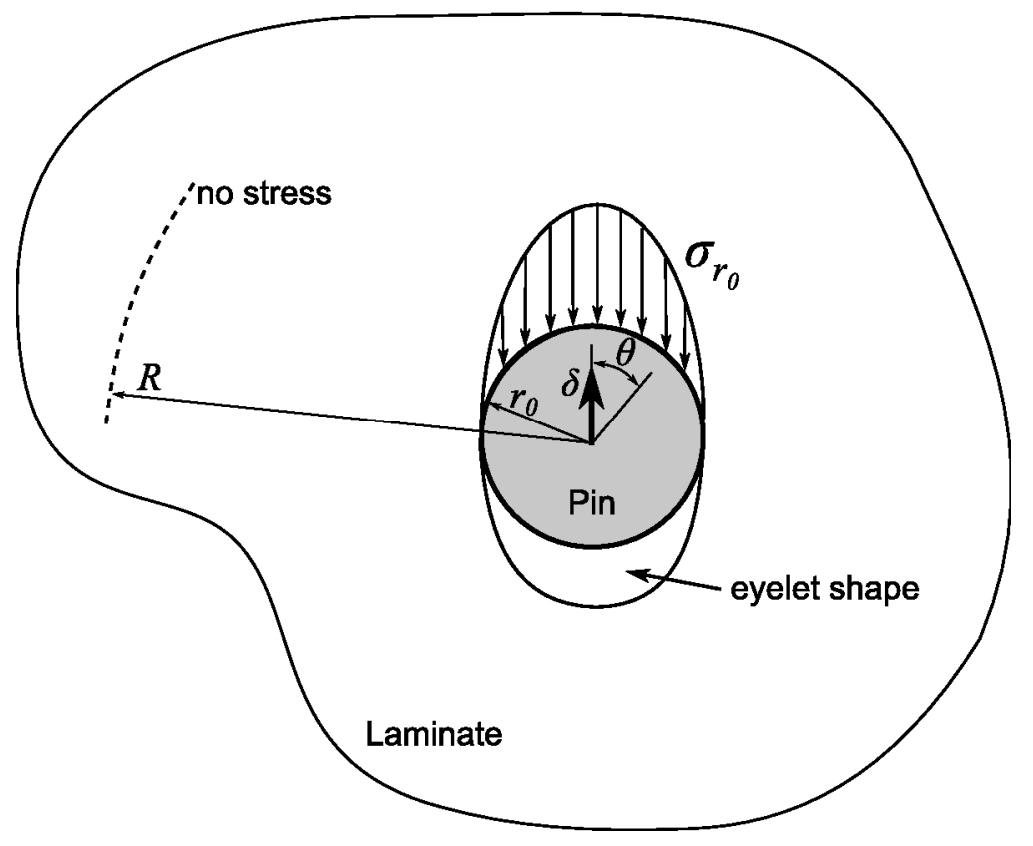

Fig. A1 Schematic of the reaction force from the laminate supporting the pin under lateral deflection.

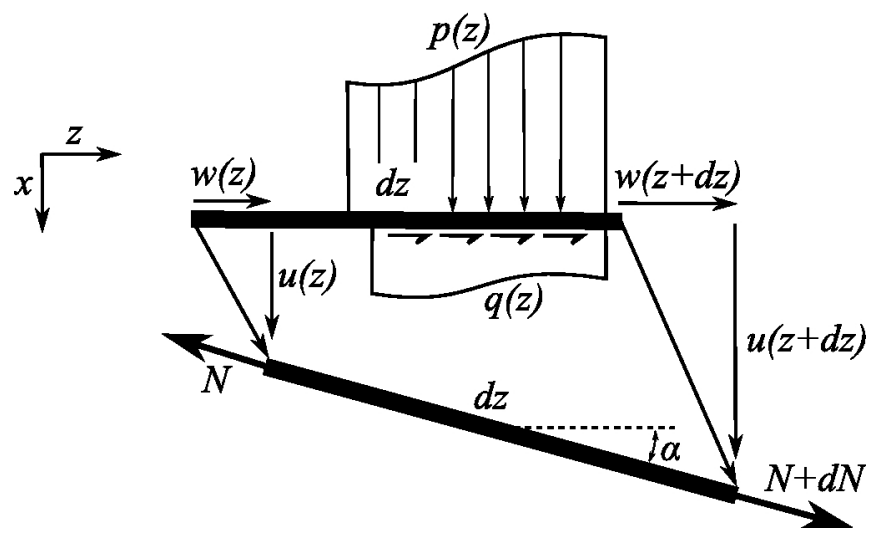

Fig. B1 Schematic of the forces acting over a pin (idealised as a truss) during the ploughing phase. 